\title{
Knowth passage-grave in Ireland: An instrument of precision astronomy?
}

\author{
Kate Prendergast \\ University of Oxford, Oxford, U.K. Email: katebrodgar@gmail.com
}

\begin{abstract}
Knowth is one of three large monuments at the Neolithic complex in the bend of the River Boyne in County Meath, Ireland. The others are Newgrange and Dowth. All three have obvious solar alignments but whereas the alignment to the winter solstice sunrise at Newgrange has been extensively researched and interpreted, little has been attempted regarding the way that astronomy functions at Knowth and Dowth. This paper treats the evidence for solar and lunar alignments at Knowth.

Knowth has two internal passages with entrances at the east and west. The paper draws on new surveys as well as interpretations of the evidence at Knowth that includes rock art engraved on kerbstones around the circumference. Particular engravings on kerbstone K52 are interpreted as depicting astronomical cycles. It is argued that, while Knowth's passages function in relation to the equinoxes, they are not internally orientated to match exactly the equinoctial directions. Rather, it seems that they may have been constructed and used to facilitate the harmonisation of the solar and lunar cycles - much in the same way as does the equinoctial Judeo-Christian festival of Easter. The paper concludes by suggesting that like Newgrange, Knowth may be an astronomical instrument that enabled its builders and users to construct accurate calendars and counting systems, which in turn facilitated calculated planning and was a fundamental structuring principle for their ritual lives and cosmological beliefs.
\end{abstract}

Keywords: astronomy; counting; Dowth; equinox; Knowth; moon; Newgrange

\section{Introduction}

The three large Neolithic monuments at the prehistoric complex on the banks of the river Boyne in County Meath, Ireland, are called Newgrange, Knowth and Dowth. Astronomical alignments comprise a central function of these monuments (see for example, O' Kelly 1982; Moroney 1999; Ruggles 1999). Astronomy at Newgrange has been extensively researched and interpreted, but less work has been done on the way that astronomy functions at Knowth and Dowth. This paper focuses on the evidence for astronomical alignments at Knowth, and on interpretations of this evidence.

Whereas at Newgrange there is a single passage facing south-east, at Knowth there are two passages. One faces approximately east and the other approximately west. For many

Published by the School of History, Classics and Archaeology, University of Edinburgh ISSN: 2055-0472. URL: http://journals.ed.ac.uk/lithicstudies/

This work is licensed under a Creative Commons Attribution 2.5 UK: Scotland License. 
years it was said without proof that these are equinoctial solar alignments, aligned on the rising and setting sun at the vernal (spring) and autumn equinoxes respectively, hence directly complementing the winter solstice rising sun alignment at Newgrange. This paper considers new surveys at Knowth, and a synopsis of this evidence is presented and reviewed in the context of the megalithic rock art at the site, of which some prominent examples can be interpreted as depicting astronomical cycles.

Furthermore, whereas Knowth's passages do function in relation to the equinoxes, precise survey and other evidence shows that internally they are not direct equinoctial alignments. Instead, it is suggested that the intention may have been to facilitate the harmonisation of the solar and lunar cycles.

Before exploring the evidence at Knowth in detail, we need a brief explanation of what we mean by 'precision astronomy' when discussing astronomy at the Boyne valley sites, and what is being defined and communicated by and through the use of this term.

Ruggles (2005: 348) has suggested that 'precision astronomy' refers to the fine-grained detail or nature of measurements, so a frequent topic of discussion in prehistoric astronomy is whether it was as 'precise' as with current astronomy. There is, rightly, a focus on questions such as what a solstice is, how it is measured, and whether the people of prehistory could measure a true 'solstice'. As we discover and document more evidence that our Neolithic ancestors understood such 'precise' astronomical concepts and events, this in turn reveals that 'precision' so defined may not be the critical issue. Rather, there needs to be a greater focus on what the people wanted this information and knowledge for. In other words, to what purposes was such astronomical knowledge put, whether or not it was truly 'precise'?

It is unlikely that we can definitively answer this question. Nonetheless, as we continue to reconstruct the levels of astronomical knowledge understood and recorded by our Neolithic ancestors, we can make the connection between this and other abundant evidence for their rich artistic and ritual lives - and suggest the many ways in which they were intrinsically linked.

\section{Evidence for astronomy at the Boyne valley monuments: Knowth in context}

I have argued elsewhere that the three large passage-graves at the Boyne valley should be seen as a single monumental complex - and that this evidence is critical for understanding the role of astronomy at each individual monument and as an inter-related group (Prendergast 2004). The inter-relatedness of the three great monuments is demonstrated through a focus on four aspects of their sequences: (1) the similarities in their structural and decorative features, (2) the common chronological horizon for their construction and use, (3) the inter-visibility of the three mounds, and (4) their central focus within the site as a whole (2004: 13-15).

It is the similarities in the structural and decorative features and common chronological horizon of all three monuments that may offer the best evidence that astronomy functions as a common, interrelated, feature across all three monuments. These major passage-graves are built to a common design. Each is a grand cairn over an acre in area, approximately 10m high, covering passages and chambers constructed with orthostats, lintels and capstones. All three cairns have kerbs of massive contiguous slabs laid on their edges surrounding the external base of the mound. The kerbstones, the passage and chamber orthostats, lintels and capstones at all three sites are profusely decorated with elaborate rock art. The dominant motifs are spirals, wavy lines, concentric circles, dots, zigzags and chevrons (Eogan 1986: 44-65).

Finds from the three passage-graves also appear to indicate a shared set of material culture. At Newgrange and Knowth identical stone basins, pendants, pins and beads were found, as well as human skeletal and cremated remains (O'Kelly 1982: 104-7; Eogan 1986: $39-43)$. 
Available radiocarbon dates indicate that the building of the three main passage-graves occurred on a common chronological horizon ca. 3200-3000 BCE (Grogan 1991; Smyth 2009).

This shared design, based on enclosed and aligned passages, with related megalithic art, would appear to have been employed to facilitate astronomical measurements and impart astronomical information at all three monuments. This would support and contextualise the unique evidence for astronomical alignments at Knowth. Moreover, a common set of associated finds and a shared chronological horizon strongly indicate that the three sites barely a mile apart - were built to function together, and their individual astronomical properties should be understood in this context.

\subsection{Astronomy at Newgrange}

Of the three passage-graves, there is no doubt that Newgrange has received the most attention. It was the first to be re-discovered in 1699, by landowner Charles Campbell. It has been excavated several times, most recently and notably by Prof. Michael O'Kelly, who also undertook an ambitious reconstruction programme of the monument. Stories about an astronomical alignment at Newgrange were popular for hundreds of years. Indeed, oral traditions regarding astronomical alignments at the Boyne valley sites were faithfully passed on throughout the medieval period during which time the monuments were abandoned, and continued into the modern phase of the monument's history. O'Kelly finally ended the speculation when his team directly witnessed the winter solstice sunrise alignment at Newgrange on 21 December 1972 (O’Kelly 1982: 124).

O'Kelly's reconstruction of Newgrange has preserved its original alignment. Today, one can fully partake of the experience of the sun entering the 'roof box' above the entrance at Newgrange on the morning of the winter solstice, and for around 11 days before and after the solstice. At the same time, excavation has allowed systematic testing of this eyewitness experience. It is now proven that the alignment at Newgrange is a 'precision alignment'.

Jon Patrick has proved that the winter solstice orientation was operative when Newgrange was constructed, and therefore is an original, central and permanent feature of the monument (Patrick 1974). Tim O'Brien has shown that the chamber and passage are sophisticated complex constructions, designed to maximise the accuracy and length of the beam of light entering the chamber (O'Brien 1988). On the basis of his research, O' Brien argues that at the time of construction, the beam of light entering the passage at Newgrange was so precisely framed by the roof-box that it could be used to calculate the exact day of the solstice itself (1988: 55-9).

This has meant we have, in turn, been able to build on this evidence and suggest how and why astronomy may have functioned in relation to the architecture, the rock art, and ritual practices at the site. This includes speculation about the role of the winter solstice as a key point that structured many aspects of social and economic life, including ritual, as the major astronomical moment so clearly identified and venerated at Newgrange (Prendergast 2012; Hensey 2015).

\section{Astronomy at Knowth: Alignment of the passages}

If the evidence at Newgrange has been so painstakingly reconstructed, what about Knowth?

Limited excavations took place at Knowth in 1941, which established the existence of decorated kerbstones and its contemporaneity with the other Neolithic cairns. However, Knowth remained largely silted over and nothing was known of its passages. In 1962 it remained the largest unopened mound in Ireland. Prof. George Eogan began excavations at 
Knowth and the surrounding landscape in 1963 (Eogan 1986). These undertakings were completed around 40 years later, together with a (somewhat controversial) reconstruction of the mound, its passages, kerbstones and surrounding features.

At Knowth Tomb 1, two passages were discovered within the main mound, running approximately east and west (Figure 1).

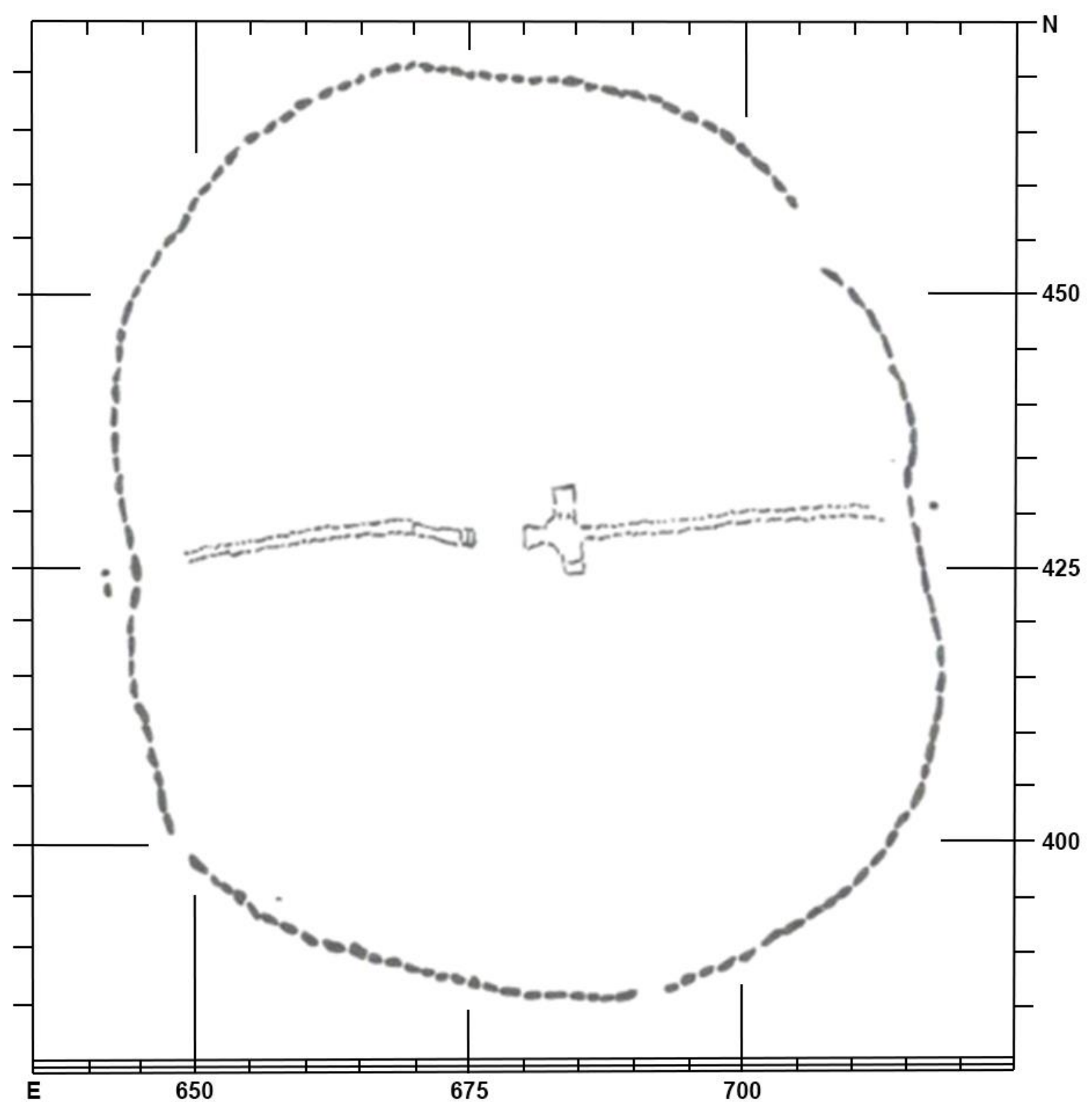

Figure 1. Plan of Knowth showing the two passages and the standing stones outside their entrances. The kerbstone positions are located after Eogan (1986: 31) but the map has been reset on the Irish Ordnance Survey grid, while noting that true north is 1 degree 13' west of grid north (see also Prendergast \& Ray 2015). Each northing is to be preceded by 273 , thus N 273400, and each easting by 299, thus E 299700).

The eastern passage is $40.4 \mathrm{~m}$ long (Figure 2), and the western passage is $34.2 \mathrm{~m}$ long. Both lead to recessed chambers. The eastern chamber is a complex cruciform structure, similar in construction to the chamber at Newgrange.

The most obvious astronomical alignments suggested by the approximate east and west alignments at Knowth are to the rising and setting sun on the autumn and vernal equinoxes. Equinoctial alignments at Knowth have been suggested by Eogan (1986: 178) and appear to 
be verified by eyewitness observations of the orientation of Knowth West by independent researcher Martin Brennan (1983).

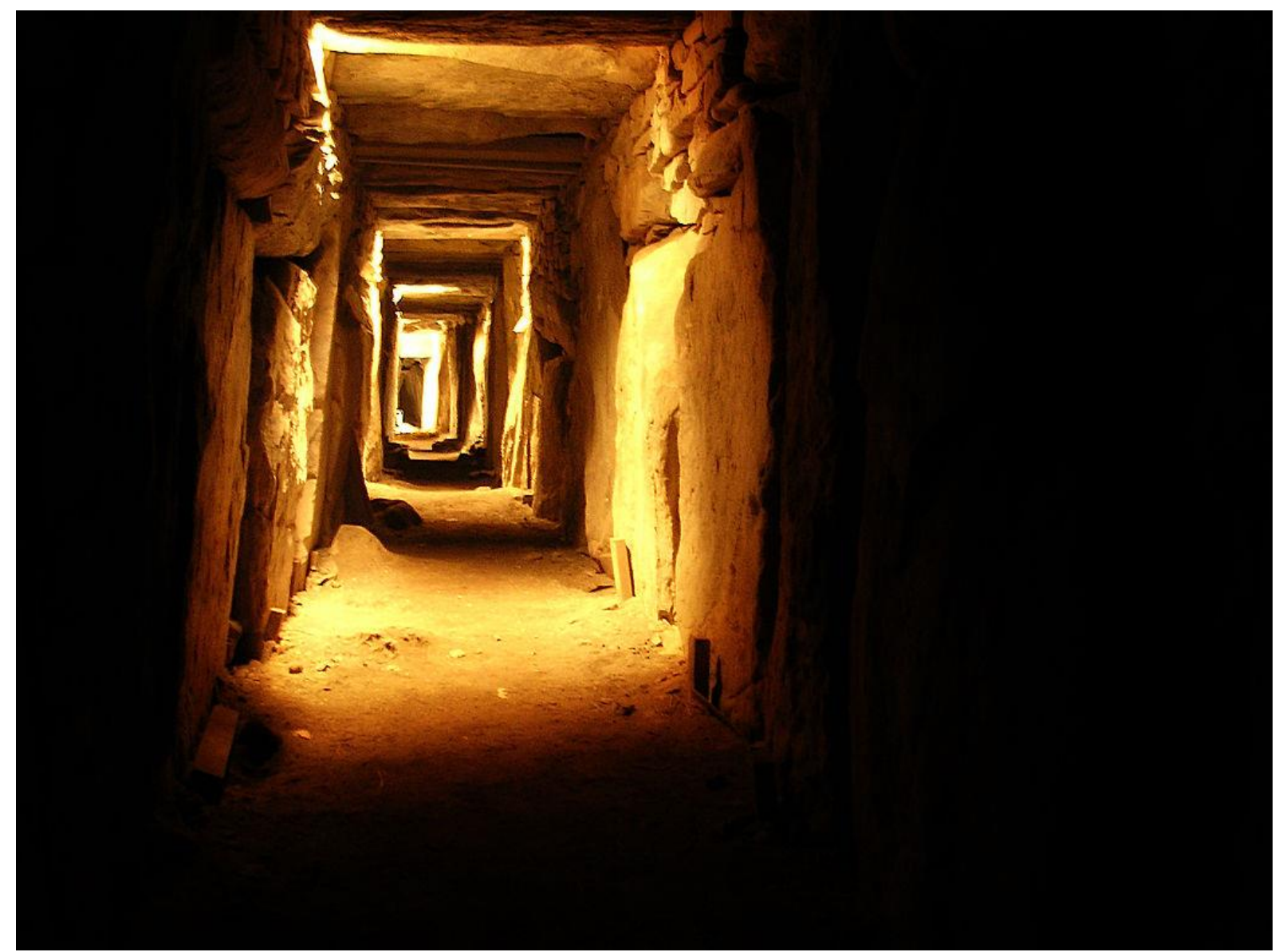

Figure 2. Eastern Passage, Knowth, County Meath, Ireland. (Photo by P. Sakradja 2005).

Brennan and colleagues were able to document and photograph the setting sun entering the west passage at Knowth around the autumnal equinox in 1980. He at first entered the west passage at Knowth at sunset on 13 September 1980, around nine days before the equinox, and found clear evidence for the penetration of direct sunlight into the passage (Brennan 1983: 57$8)$.

On 16 September, the team, with a photographer, returned to Knowth at sunset, and again recorded the movement of light and shadow from both inside the western passage and outside, on the entrance stones. The observations appeared to confirm that as equinox approached, the shadow of the standing stone moved closer to the vertical line on the entrance stone, and the beam of light penetrated further into the chamber.

Brennan and his team recorded their eyewitness accounts but were unable to survey the passage alignment at Knowth West. This work has since been undertaken by Frank Prendergast and Tom Ray and their findings provide the level of precision needed to analyse possible alignments. They argue that: "The findings indicate that contrary to earlier suggestions, the eastern passage and the western passage (inner and outer) are not aligned towards sunrise and sunset respectively at the period of the vernal and autumnal equinoxes." (2015: ii).

Their survey of the passage and entrance indicates that the sun most deeply penetrates the passage of Knowth West at sunset, not on the equinoxes but just over two weeks after the autumnal equinox or equivalently just over two weeks before the vernal equinox (2015: 6). In 
other words, while Brennan's eye-witness observations appeared to show the sun moving closer to the standing stone and the vertical line on the entrance kerbstone as the autumn equinox approached, survey data indicates the full alignment at Knowth West does not occur until two weeks after the autumn equinox has passed.

The same survey data indicate that at Knowth East, the rising sun enters the passage some six days before the equinoctial rising sun in the autumn and around six days after the rising sun at vernal equinox (2015: 11).

\subsection{Precision alignments at Knowth}

As we have seen, O'Brien has argued that the winter solstice alignment at Newgrange was so accurate it could predict the day of the solstice. Do the alignments at Knowth reveal a similar level of precision? In this context it is worth noting that the solstice - which is the shortest day - can vary by a day or so each year in the Gregorian calendar. So while simple day-counts from solstice to equinox to solstice can establish the approximate day of the equinox, it will not identify the exact day as to when the sun shines along either passage when near the equinoxes.

As Brennan has noted, an instrument like an aligned passage in a monument that accurately measures real-time phenomena can do this far more effectively (1983: 41-5). Aligned passages are more accurate versions of a sun-dial or gnomon. Instead of casting a shadow, the passage narrows a beam of light as it is projected into the chamber. This is not only a particularly accurate form of solar measurement; it also gives warnings of forthcoming solar events. Given the minimal shifts in the obliquity of the ecliptic over millennia, a passage is also a permanent structure, which does not need re-alignment and will continue to provide accurate observations once it is constructed.

Whereas solstice means 'standstill' - because the sun moves so slowly on the horizon during this time - at equinox the sun is moving fast on the horizon - by nearly as much as a solar disc a day during the equinox itself. This has led Ruggles (1997) to argue that defining and measuring the equinox precisely is more difficult than for the solstice - and thus to question whether prehistoric peoples would have known what the equinox was or had any interest in it at all.

Other archaeo-astronomers, including Antony Murphy and Richard Moore, point to the range of evidence available at Knowth's two passage alignments to argue that far from being misinterpreted as equinox alignments, the passages at Knowth may perform an even more complex function (Murphy \& Moore 2006: 189-92). Murphy and Moore argue they may have been designed and used to calibrate the harmonization of the solar and lunar cycles, using the moon at the equinox to count one cycle in the context of another - in much the same way as does the Jewish festival of Passover and its Christian counterpart, Easter.

If the passages at Knowth can be interpreted as facilitating observations that integrate the lunar and solar cycles, this would make it an instrument designed to measure a 'moveable feast', in contrast to Newgrange that is designed to measure a fixed point. The main reason for this is because the lunar cycle does not a priori harmonise with the solar cycle, made up of points like the solstice. There are up to 13 synodic lunations of 29 days in every synodic or tropical solar cycle or year of 365.24 days (the time it takes for the earth to do a full circle of the sun). Over time, a count based on the lunar cycle alone would drift in relation to the seasons. So, in order to properly align the solar year with the lunar cycle, astronomers measure a fixed point like the solstice and the movements of the moon in relation to such solar points. It is possible, therefore, that just as Newgrange enables precision measurement of the winter solstice, Knowth may facilitate observation of the moon in relation to the sun at equinox, in order to establish a system for aligning the two cycles. 
Gillies MacBain (2006) has suggested a specific counting system that may be facilitated by these alignments. MacBain argues that Knowth East (vernal equinox plus 6 days) marks three synodic lunar months (of 29 days) before the summer solstice, six synodic lunar months before the autumn equinox and nine synodic lunar months before the winter solstice. Knowth West, MacBain (2006) argues, marks thirteen synodic lunar months before the following vernal equinox.

This evidence would need further exploration and verification before it is proven, but it certainly raises some very interesting possibilities about the more complex ways that solar and lunar alignments may work at Knowth. Moreover, this may be supported by other evidence that we have for an interest in the moon at Knowth.

Terence Meaden (2017) introduces the additional point that, although the sun does not shine along the passages to its fullest extent at the equinoxes at Knowth, the shadow of an outer standing stone does achieve union with the vertical line engraved on the kerbstones in front each passage at the equinoxes as determined by means of day-counting.

\subsection{Rock art at Knowth: Representing harmonisation of the solar and lunar cycles?}

Stone K52 (on Eogan's numbering scheme, 1986: 132) (Figure 3) is one of the kerbstones at Knowth, and is also known as the Calendar Stone. As many researchers have argued, it may be a representation of the moon's monthly cycle, or the synodic month (see for example, Brennan 1983: 144).

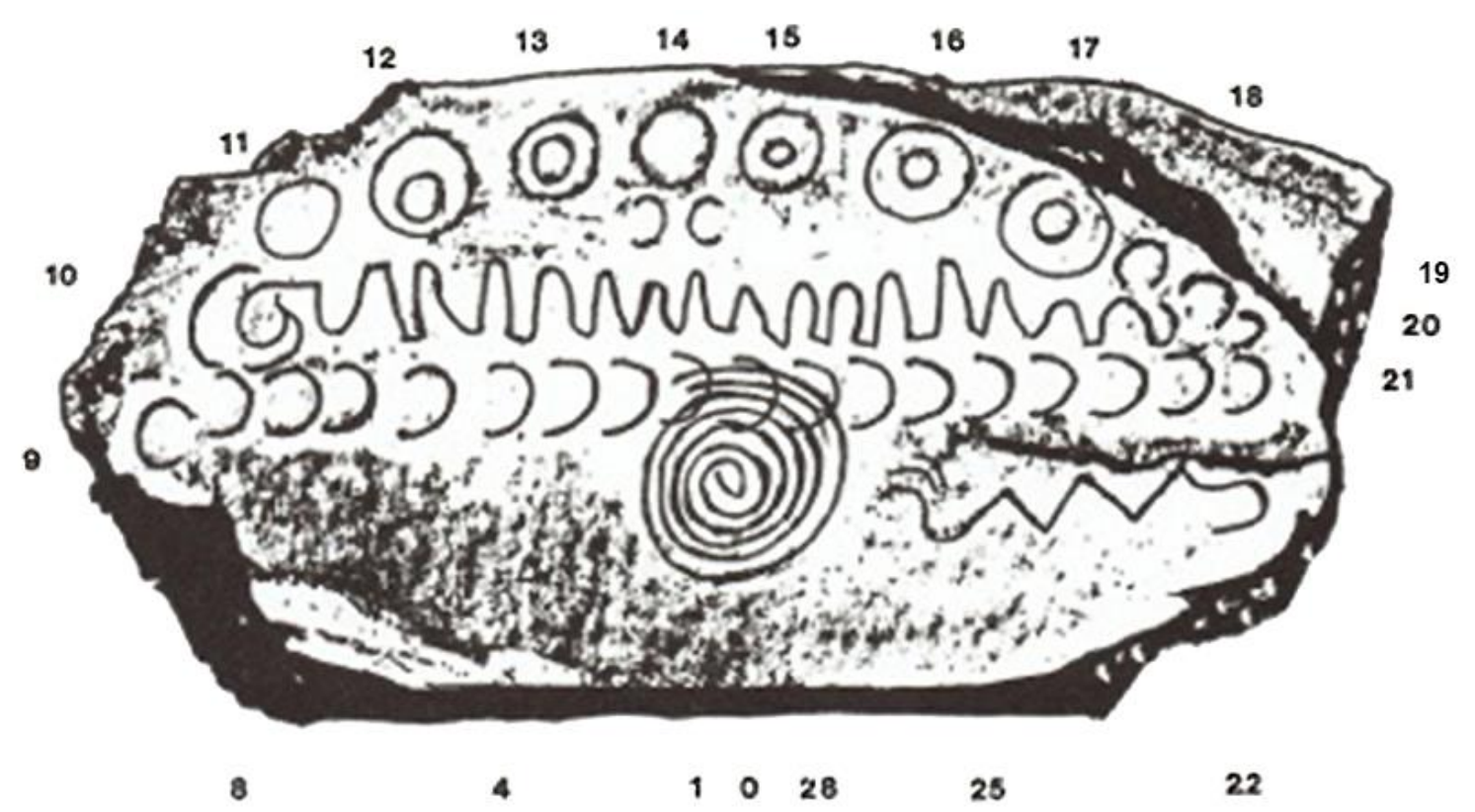

Figure 3. Calendar stone K52 at Knowth (figure from Meaden 1991: 125).

Twenty-nine circles and crescents are carved around the long wavy line in the middle of the stone. These appear to represent the monthly cycle of the moon. Counting clockwise, the new moon is the first crescent to emerge from the spiral. Crescents become circles through the moon's waxing phase until it reaches full moon - the circle at the top of the stone. Circles become crescents again through the moon's waning phase. The nights of dark moon (the three nights of the month when the moon is not visible) are represented by the three crescents in the spiral. The new moon emerges from the spiral and the monthly cycle is repeated.

Moreover, it has been claimed that the lunar counting system on K52 is even more complex. It can be used to calculate the harmonisation of the lunar and solar cycles over five 
solar years (Brennan 1983: 144). 12 lunar months are just over 354 days, but a solar year is just over 365 days. Hence, every five solar years, there will be two 'extra' - or 62 - lunar months. The wavy line in the middle of the stone counts out 31. Each turn represents the lunar month depicted in crescents and circles around it. The line reverses, to count to 62 which is the number of lunar months in five solar years. The reversal of the line at 31 harmonises the lunar count with the equinoxes as there is one extra lunar month every two and half years.

Murphy and Moore have claimed that the Calendar Stone can be used to map even more complex astronomical cycles, including the 'Metonic Cycle', named after an Athenian astronomer called Meton (2006: 196). In the Metonic Cycle, the sun and moon harmonise over 19 solar years, which equals 235 synodic months. At the bottom-right hand corner of K52 there is a wavy line that counts out seven. Seven multiplied by 31 - the count of the wavy line in the middle of the stone - equals 217 . Half way along the wavy line there are two small crescents, where the wavy line count stops at 18. Add 18 to 217 and one has 235: the number of lunar months in a 19-year solar cycle.

Murphy and Moore (2006: 197) have further argued for a similar interpretation of kerbstone K53 - also known as the 'Lunar Stone' - at Knowth, viz. that its profusion of circles, crescents, waves, spirals and lines also can be used to count the sidereal and synodic lunar months. Both are critical for measuring the Metonic Cycle.

Comprehensive surveys of the rock art in the region have been undertaken by several researchers, including those that suggest a consistent and wide ranging inter-relationship between the rock art and astronomy (See for example, Van Hock 1987, 1988). One further example at Knowth includes kerbstone K15 - also known as the 'sundial stone' (Figure 4).

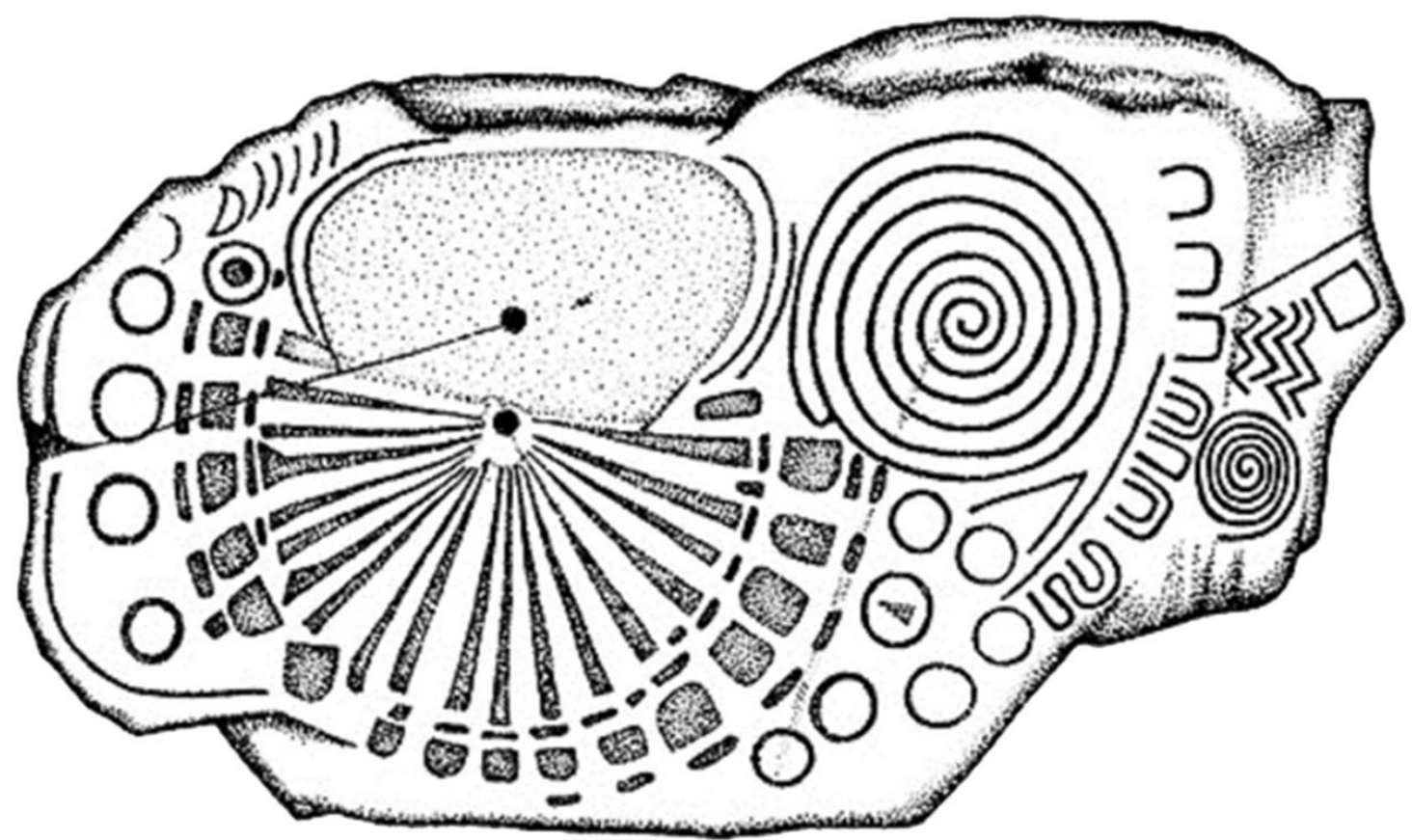

Figure 4 Kerbstone K15 at Knowth - the 'sundial stone'.

The central image on this stone has been interpreted as a depiction of a sundial, with the extreme positions reached by the sun on the horizon - the summer and winter solstices marked at the extreme radial shadows or 'spokes' thrown from the central gnomon, with the equinox marked as equidistant between these two extreme points (Brennan 1983: 190-1). An interest in the lunar cycle is also suggested by the presence of crescents and circles on each side of the stone - in turn indicating, and adding to the evidence for a combined interest in the solar and lunar cycles at Knowth (Wun 2008: 15). Euan Mackie (2009; 2013) has 
corroborated such interpretations by arguing K15 should be interpreted as "an exact representation on stone of the sixteen-month solar calendar" (2009: 26) - the so-called prehistoric calendar as first suggested by Alexander Thom, former Professor of Engineering Science at the University of Oxford.

\section{Conclusion}

If the survey of the passages and the rock art evidence at Knowth both point to an interest in, and emphasis on, the alignment of solar and lunar cycles, how might we interpret this evidence from a cultural perspective? First, it suggests a comparable interest in precision astronomy at Knowth demonstrated at Newgrange. The alignment of the Knowth passages, and associated rock art, may not display an interest in basic alignments but in sophisticated calculations, possibly designed to both identify the equinoxes and facilitate the counting of the moon's cycles in relation to the sun. If so, this evidence would strengthen the case for precision astronomy at the Boyne valley sites as a whole. Moreover, it further suggests that the alignments at Knowth work with the alignments at Newgrange. The builders of Newgrange chose to measure the winter solstice. The builders of Knowth chose to measure the equinoxes in relation to the moon. If we note evidence for further alignments at other sites in the Boyne valley (and beyond) that complement those at Newgrange and Knowth, we can begin to see that Neolithic astronomers may have been able to map the cycles of the planets and stars at a sophisticated level - pointing to a society with a level of knowledge that could be embedded into permanent instruments in the landscape.

This in turn enabled that knowledge to be passed on to future generations - including our own. It is therefore vital that we preserve and continue to analyse and interpret these astronomical megalithic instruments, so that we too can be part of this great endeavour to understand and pass on this precious knowledge to the people of the future.

\section{References}

Brennan, M. 1983, The Stars and the Stones. Thames and Hudson, London, 208 p.

Eogan, G. 1986, Knowth and the Passage Tombs of Ireland. Thames and Hudson, London, $147 \mathrm{p}$.

Grogan, E. 1991, Appendix: radiocarbon dates from Brugh na Boinne. In: Eogan, G. (Ed.), Prehistoric and early historic change in Brugh na Boinne. Proceedings of the Royal Irish Academy, 91(C): p. 126-127. Retrieved 21 November 2016.

URL: https://www.jstor.org/stable/25516079

Hensey, R. 2015, First Light: The Origins of Newgrange. Oxbow, Oxford, 200 p.

MacBain, G. 2006, Finding Easter at Knowth. Irquas Insight, (3). Retrieved 11 November 2016. URL: http://homepage.eircom.net/ archaeology/three/knowth.htm

Mackie, E.W. 2009, The Prehistoric Solar Calendar: An Out of Fashion Idea Revisited with New Evidence. Time and Mind, 2(1): 9-46.

URL: http://www.tandfonline.com/doi/pdf/10.2752/175169709X374263

Mackie, E.W. 2013, A Rosetta Stone for the Prehistoric Solar Calendar? Kerbstone K15 at Knowth, Ireland. Time and Mind, 6(2): 211-229. doi:10.2752/175169713x13589680081894

Meaden, G.T. 1991, The Goddess of the Stones: The Language of the Megaliths. Souvenir Press, London, 224 p. 
Meaden, G.T. 2017, Drombeg Stone Circle, Ireland, analyzed with respect to sunrises and lithic shadow-casting for the eight traditional agricultural festival dates and further validated by photography. Journal of Lithic Studies, 4(4): 5-37 p. doi:10.2218/jls.v4i4.1919

Moroney, A.M. 1999, Winter Sunsets at Dowth. Archaeology Ireland, 13: 29-31.

Murphy, A., \& Moore, R. 2006, Island of the Setting Sun. In Search of Ireland's Ancient Astronomers. The Liffey Press, Dublin, 340 p.

O'Brien, T. 1988, Winter solstice and decoration at Newgrange. Riocht Na Midhe, 8(2): 5059.

O’Kelly, M. 1982, Newgrange. Thames and Hudson, London, 232 p.

Patrick, J. 1974, Midwinter Sunrise at Newgrange. Nature, 249: 517-519. doi: $10.1038 / 249517 \mathrm{a} 0$

Prendergast, K. 2004, Caves of the winter sun. Synthesising the evidence for astronomical orientation at the Boyne valley passage tombs. Riocht Na Midhe, 15: 12-25.

Prendergast, K. 2012, The Neolithic Monument of Newgrange in Ireland: A Cosmic Womb? In: Archaeology of Mother Earth Sites and Sanctuaries through the Ages: Rethinking symbols and images, art and artefacts from history and prehistory (Meaden, G.T. Ed.), Archaeopress, Oxford: p. 57-64.

Prendergast, F., \& Ray, T. 2015, 'Alignment of the western and eastern passage tombs at Knowth Tomb 1', Appendix 2. In: Excavations at Knowth 6: The Great Mound at Knowth (Tomb 1) and its passage tomb archaeology (Eogan, G., \& Cleary, K., Eds.), Royal Irish Academy, Dublin: p. 1-17. URL: http://arrow.dit.ie/arastbk/3/

Ruggles, C.L.N. 1997, Whose Equinox? Journal of the History of Astronomy, 28: 44-50. doi:10.1177/002182869702802205

Ruggles, C.L.N. 1999, Astronomy in Prehistoric Britain and Ireland. Yale University Press, London, $285 \mathrm{p}$.

Ruggles, C.L.N. 2005, Ancient Astronomy: An Encyclopaedia of Cosmologies and Myth. Santa Barbara, ABC-CLIO, 518 p.

Sakrajda, P. 2005, Eastern Passage, Knowth, County Meath, Ireland. Wikimedia Commons. Retrieved: 11 November 2016. URL:

https://commons.wikimedia.org/wiki/File:Knowth.jpg

Smyth, J. (Ed.) 2009, Brú na Bóinne World Heritage Site Research Framework. The Heritage Council, Dublin, 151 p.

URL: http://www.worldheritageireland.ie/fileadmin/user_upload/documents/BrunaBoin neWHSResearchFramework.pdf

Van Hock, M.A.M. 1987, The Prehistoric Rock Art of County Donegal (Part I). Ulster Journal of Archaeology, 50: 23-46. URL: https://www.jstor.org/stable/20567997

Van Hock, M.A.M. 1988, The Prehistoric Rock Art of County Donegal (Part II). Ulster Journal of Archaeology, 51: 21-47. URL: https://www.jstor.org/stable/20568110

Wun, C.B. 2008, The Gods' Machines: From Stonehenge to Crop Circles. Frog Books, Berkeley, $528 \mathrm{p}$. 